\title{
A THERMAL IMAGING INSTRUMENT WITH UNCOOLED DETECTORS
}

\author{
A. T. Joseph ${ }^{1}$, E. Barrentine ${ }^{2}$, and A. Brown ${ }^{2}$ \\ ${ }^{1}$ Hydrological Sciences Laboratory/617, Hydrospheric and Biospheric Sciences Directory, \\ NASA/Goddard Space Flight Center (GSFC), Greenbelt, MD 20771 USA, Tel: 301-614-5804, Fax: 301 - \\ 614-5808, e-mail: Alicia.T.Joseph@ nasa.gov \\ ${ }^{2}$ Code 553, NASA/Goddard Space Flight Center (GSFC), Greenbelt, MD 20771 USA, e-mail: \\ Emily.M.Barrentine@nasa.gov, Ari.D.Brown@nasa.gov
}

\begin{abstract}
In this work, we performed an instrument concept study for sustainable thermal imaging over land with uncooled detectors. We evaluated two different uncooled detector technologies uncooled microbolometers and thermopiles. We have also evaluated materials for use in in a uncooled thermopile detector concept.
\end{abstract}

Index Terms - Thermal, uncooled, detectors, imaging, instrument

\section{INTRODUCTION}

The National Research Council's Committee on Implementation of a Sustained Land Imaging Program has identified the inclusion of a thermal imager as critical for both current and future land imaging missions. Such an imaging instrument operating in two bands located at approximately 11 and 12 microns (for example, in Landsat 8, and also Landsat 9 when launched) will provide essential information for furthering our hydrologic understanding at scales of human influence, and produce field-scale moisture information

through accurate retrievals of evapotranspiration (ET). Landsat 9 is slated to recycle the TIRS-2 instrument launched with Landsat 8 that uses cooled quantum well infrared photodetectors (QWIPs) operating at 43-65 $\mathrm{K}$ temperature, hence requiring expensive and massive cryocooler technology to achieve its required spectral and spatial accuracies. See Fig. 1.

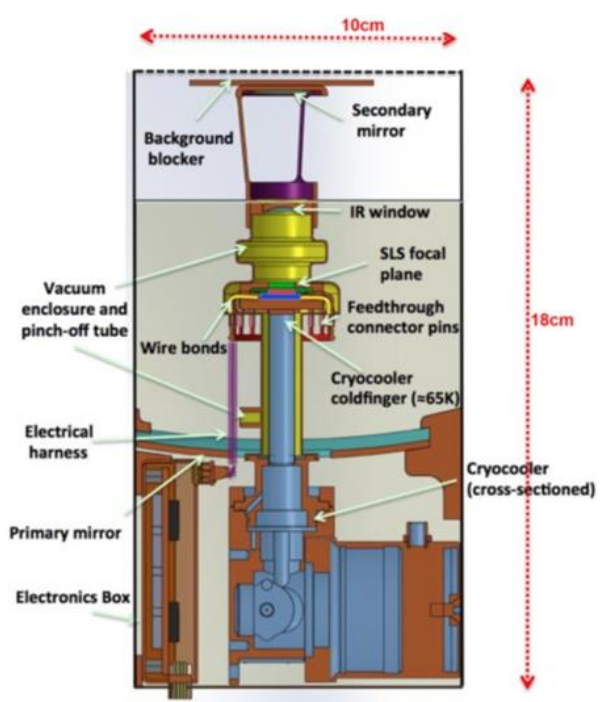

Fig. 1: Schematic of a conceptual thermal imager, which employs cryogenic strained super-lattice detectors. The cryocooler comprises $\geq 70 \%$ of the mass and volume of the imager and requires $\geq 40$ $W$ of power. We will develop an instrument concept with uncooled detectors that does not require a cryocogler. and develop a thermal imaging instrument which leverages recent and imminent 
technology advances in uncooled detectors. Such detector technology will offer the benefit of greatly reduced instrument cost, mass, and power at the expense of some acceptable loss in detector sensitivity. It would also allow a thermal imaging instrument to be fielded on board a low-cost platform, e.g., a CubeSat. In addition, it would enable capitalizing on the greater number of launch opportunities available for launch vehicles like the Evolved Expendable Launch Vehicle (EELV) Secondary Payload Adapter (ESPA).

\section{MOTIVATION}

Sustained and enhanced land imaging is crucial for providing high-quality science data on change in land use, forest health, crop status, environment, and climate. Accurate satellite mapping of ET at the agricultural field scale (the finest spatial scale of the environmental processes of interest) requires high-quality thermal data to produce the corresponding accurate land surface temperature (LST) retrievals used to drive an ET model. Such an imaging instrument would provide important information on the following: 1) the relationship between landuse and land/water management practices and water use dynamics; 2) the interconnections between anthropogenic water management and changes in hydrologic budget at scales of human influence; and 3) complimentary field-scale moisture values for interpreting coarser resolution datasets.

There is a clear need for continuing innovation in thermal remote sensing detector technology. By 2023-the scheduled launch year for Landsat 9-its thermal detector technology will be fifteen years old, and Landsat 8 will be approaching the end of its useful life. In the near term, ESA's launch of Sentinel-2, a constellation of two satellites with multi-spectral imagers, will provide high-resolution imaging in the 443-2190 nm spectral range, but with no thermal coverage.

Recent advances in uncooled detector technology, by developing novel types of ultrasensitive thermopiles like doped-silicon thermopiles - offer the prospect of realizing a viable thermal instrument.

\section{UNCOOLED DETECTOR STUDY}

In this work, we reviewed three possible lowTRL technologies: Vanadium oxide bolometers, Bi-Te thermopile technologies, and doped-Si thermopiles, a new detector concept developed by our team. For this study we compared these technologies and their potential for improvement to the current leading cooled detector technology for land imaging, Quantum Well Infrared Photodetectors (QWIPs),. See Table 1.

We modified our doped-Si design [cite Lakew] to meet TIRs instrument requirements including pixel size and speed. Based on the results of these studies we decided to pursue doped-Si thermopile technology for development efforts. Furthermore, customized bolometers are still of interest and NASA would benefit from partnering with a commercial vendor.

Detector Design Trade Study comparing QWIPS/TIRs to potential doped-Si thermopiles or potential commercial microbolometer or thermopile designs. TIRS System Requirements are $25 \mu \mathrm{m}$ pixel size; NETD $\leq 330 \mathrm{mK}$; time constant (TC) $\leq 5.5 \mathrm{~ms}$ 


\begin{tabular}{|l|l|l|l|l|}
\hline $\begin{array}{l}\text { Uncooled } \\
\text { Detector Choice }\end{array}$ & $\begin{array}{l}\text { Focal Plane } \\
\text { Temperature }\end{array}$ & NETD & $\begin{array}{l}\text { Detector } \\
\text { TC }\end{array}$ & Pixel Size \\
\hline $\begin{array}{l}\text { Customized } \\
\text { IPHT Thermopile }\end{array}$ & $300 \mathrm{~K}$ & $\sim 3400 \mathrm{mK}$ & $\sim 5.5 \mathrm{~ms}$ & $25 \mu \mathrm{m}$ \\
\hline $\begin{array}{l}\text { Customized } \\
\text { JPL Thermopile }\end{array}$ & $300 \mathrm{~K}$ & $\sim 2300 \mathrm{mK}$ & $\sim 5.5 \mathrm{~ms}$ & $25 \mu \mathrm{m}$ \\
\hline $\begin{array}{l}\text { Customized } \\
\text { JPL 2D Thermopile }\end{array}$ & $300 \mathrm{~K}$ & $\sim 1850 \mathrm{mK}$ & $\sim 5.5 \mathrm{~ms}$ & $25 \mu \mathrm{m}$ \\
\hline $\begin{array}{l}\text { Proposed } \\
\text { GSFC Doped-Si } \\
\text { Thermopiles }\end{array}$ & $300 \mathrm{~K}$ & $\sim 3100 \mathrm{mK}$ & $\sim 5.5 \mathrm{~ms}$ & $25 \mu \mathrm{m}$ \\
\cline { 2 - 5 } & $170 \mathrm{~K}$ & $\sim 1140 \mathrm{mK}$ & $\sim 5.5 \mathrm{~ms}$ & $25 \mu \mathrm{m}$ \\
\hline $\begin{array}{l}\text { Customized } \\
\text { INO Vox } \\
\text { Microbolometer }\end{array}$ & $300 \mathrm{~K}$ & $\sim 443 \mathrm{mK}$ & $\sim 5.5 \mathrm{~ms}$ & $35 \mu \mathrm{m} *$ \\
\hline $\begin{array}{l}\text { Customized } \\
\text { SCD Vox } \\
\text { Microbolometer }\end{array}$ & $300 \mathrm{~K}$ & $\sim 796 \mathrm{mK}$ & $\sim 5.5 \mathrm{~ms}$ & $25 \mu \mathrm{m}$ \\
\hline $\begin{array}{l}\text { Proposed } \\
\text { GSFC Doped-Si } \\
\text { Thermopiles } \\
\text { W/ 'holey' Si }\end{array}$ & $\mathbf{3 0 0 \mathrm { K }}$ & $\sim 420 \mathrm{mK}$ & $\sim 5.5 \mathrm{~ms}$ & $25 \mu \mathrm{m}$ \\
\cline { 2 - 5 } & $170 \mathrm{~K}$ & $\sim 161 \mathrm{mK}$ & $\sim 5.5 \mathrm{~ms}$ & $25 \mu \mathrm{m}$ \\
\hline \begin{tabular}{l} 
GSFC QWIPS \\
\hline
\end{tabular} & $43 \mathrm{~K}$ & $16 \mathrm{mK}$ & $<5.5 \mathrm{~ms}$ & $25 \mu \mathrm{m}$ \\
\hline
\end{tabular}

Table 1: Comparison of vanadium oxide bolometers, skutterudite thermopiles, and doped-Si thermopiles and current leading cooled detector technology for land imaging, Quantum Well Infrared Photodetectors (QWIPs), and commercial uncooled detector options and their potential for improvement.

\section{REFERENCES}

[1] T. H. Geballe and G. W. Hull, "Seebeck Effect in Silicon," Phys. Rev., 98, 940 (1955).

[2] C. S. Allison, et al., "A bulk micromachined silicon thermopile with high sensitivity," Sensors and Actuators A, 104, 32-39 (2003).

[3] U. Florin, et al.,"IR thermopile detector," Patent no. WO2013167875 A1 (2013).

[4] D. F. Paige, "Microfabricated silicon thermopile sensor," US Patent no. US5982014A (1999).
[5] R. P. Brekosky, et al., "Fabrication process responsible for fundamentally improving Silicon X-ray microcalorimeter arrays," Nucl. Instr. And Meth. in Phys. Res. A 520, 439-442 (2004).

[6] R. L. Kelley et al., "The Suzaku High Resolution X-ray Spectrometer," Publ. Astron. Soc. Jap. 59, S77-S112 (2007).

[7] T. Takahashi et al., "The Astro-H X-ray Observatory," Proc. of SPIE 8443, $84431 \mathrm{Z}$ (2012) 